\title{
The Reasons Behind the Trending of Facial Plastic Surgery in Saudi Arabia
}

\author{
Almuhaya Reham ${ }^{1 *}$, Alarfaj Ahmed ${ }^{2}$, Alturki Lulwah ${ }^{3}$, Layan al Tawil ${ }^{3}$, Areej Alrajeh ${ }^{3}$ and Alkarzae Mohammed \\ ${ }^{1}$ Facial Plastic division, College of Medicine, King Saud University, Riyadh, Saudi Arabia \\ ${ }^{2}$ Professor, Facial Plastic - ORL Consultant, College of Medicine, King Saud University, Riyadh, Saudi Arabia \\ ${ }^{3}$ Medical intern, College of Medicine, King Saud University, Riyadh, Saudi Arabia \\ ${ }^{4}$ Clinical Fellow in Facial Plastic division, College of Medicine, King Saud University, Riyadh, Saudi Arabia
}

*Corresponding author: Almuhaya Reham, Facial Plastic division, College of Medicine, King Saud University, Riyadh, Saudi Arabia

\begin{abstract}
Background: Nowadays, the demand of plastic surgery has dramatically increased According to the American Society of Plastic Surgery (ASPS), nearly 17 million cosmetic producers were performed in 2016 and 58\% has increased cosmetic surgery from 2012-2016 for both men and women. Media influences, medical advancements and patients' characteristics have a role in the recent upsurge of cosmetic surgery.
\end{abstract}

Objectives:

a) To find reasons for encouraging the patient to go for facial plastic surgery.

b) To asses Factors that motivate people towards plastic surgery.

c) To study the association between body dysmorphic disorder in people attending a facial plastic clinic and the desire to do an intervention.

Design: A cross-sectional study.

Settings: conducted in a facial plastic clinic in King Abdulaziz University Hospital, Riyadh, Saudi Arabia between, January to March 2018. A validated and standard electronic and paper-based questionnaire was sent to a total of 399 participants who are attending cosmetic clinics.

Methods: All 18 years of age and older who attended the facial plastic clinic for a procedure, male and female, from January to March 2018 were included.

Sample Size: A total of 399 cosmetic surgery patients participated in this study.

Results: The most common cosmetic intervention was Botox injection (41\%), and the most common facial plastic procedure was rhinoplasty (59\%). As reasons, our participants thought that what makes the facial plastic intervention trending in our population are because of social media influencers and celebrities (72.2\%). In our population, there was no association between body dysmorphic disorder and the trending of facial plastic surgery.

Conclusion: The social media and celebrities have a significant rule in trending facial plastic procedure in our region. However, there was no association between taken selfies and the desire to go for plastic intervention.

Limitations: Involving one center in one region.

Keywords: Facial Plastic Surgery; Saudi Arabia; Trending, Selfies; Social Media 


\section{Introduction}

Nowadays, the demand for plastic surgery has dramatically increased [1]. According to the American Society of Plastic Surgery (ASPS), nearly 17 million cosmetic producers were performed in 2016 making the total annual cost of cosmetic procedures around 16.4 billion USD) [2]. According to a study conducted by the International Society of Aesthetic Plastic Surgeons (ISAPS), Saudi Arabia ranks $29^{\text {th }}$ among the top 30 countries with the highest rates of cosmetic procedures in the world [3]. Cosmetic surgery has increased by 58\% from 2012 to 2016 for both men and women [4]. ASPS reported that most of the cosmetic procedures, about $92 \%$, were performed on a female and rhinoplasty was among the top five procedures done in 2015 to 2016 [2]. Multiple factors behind the trending of facial plastic surgery. Media influences, medical advancements, and patients' characteristics have a role in the recent upsurge of cosmetic surgery [5] Exposure to media and satellite television found to be contributing factors to the higher rate of rhinoplasty [6]. Furnham et al. reported that increased media exposure, low self-steam and life satisfaction would increase the chance of undergoing plastic surgery [7]. Also, interaction with surgeons and take consultations through the social media led to an increase in the number of patients searching for plastic surgery $[8,9]$. According to a poll by the American Academy of Facial Plastic and Reconstructive Surgeons, $42 \%$ of surgeons reported patients seeking cosmetic procedures to look better in selfies [10]. Taking selfies and sharing them on social media like snapchat or Facebook has increased recently [11]. A study reported by Ward B et al. showed that nasal size in selfies appears bigger by $30 \%$; therefore, this may be one of the reasons behind the increased demand on rhinoplasty [12]. Another study conducted in Iran by Rastmanesh $\mathrm{R}$ et al. [13] showed patients who had a history of cosmetic rhinoplasty have depression and body dissatisfaction with low selfsteam compared with those who did not have a history [13]. The lack of research in this field in our region and the Middle East has prompted us to undertake this study. We aimed to assess reasons of increasing plastic procedures in our community, the effect of social media in this decade and factors motivating people to undergo cosmetic procedures.

\section{Method}

A cross-sectional study was conducted in a facial plastic clinic at King Abdulaziz University hospital after the approval of the Ethical Committee of the faculty of medicine at King Saud University, Riyadh, Saudi Arabia. All 18 years of age and older who attended the facial plastic clinic for a procedure, male and female, from January to March 2018 were included. Patients who refuse to be involved in the study were excluded. Anonymous paper-based questionnaires, an electronic-based questionnaire was distributed to people who attend cosmetic clinics. The sample size was determined by using a single population proportion sample size. Estimation method with 95\% confidence interval. The questionnaire was translated to the Arabic Language. The questionnaire contained four parts; first part is about socio-demographic data which included ten closeended questions as (age, gender, education status, marital status, financial income, monthly income, previous cosmetic intervention and plastic surgery, wish/plan to do plastic interventions in the future and numbers of selfies taken per day). Part two was about Reasons behind undergoing facial plastic procedures; it included seven close-ended questions. Section three contains 15 close-ended questions, and one open-ended question about What does the patient think are the reasons behind trending of plastic surgery in the community. Last part included the validated Arabic questionnaire for screening of body dysmorphic. Data were collected using a paper-based questionnaire. The face and content validation were done by two experts. A total of 399 response was collected Then it was entered in Statistical Package for Social Sciences (SPSS) program, version 23.0 (SPSS Inc, Armonk, New York, USA), for Statistical analysis. Frequency distribution was presented in numbers and percentages (for categorical variables) and as the mean and standard deviation (for continuous variables). Fisher's Exact Test was used to determine the statistical difference between categorical groups or proportions. A p-value of less than 0.05 was considered statistically significant.

\section{Result}

A total of 399 cosmetic surgery patients participated in this study. The overwhelming majority were female 340 (85\%) and 40 years of age or younger counts for 285 (71\%). About half of the participants 205 (51\%) were married, the majority were highly educated (bachelor, master \& Ph.D.) 334 (83.8\%) \& 277 (68\%) have a monthly family income over 2600 USD (Table 1). The association between the financial status \& the facial plastic surgery was found to be statistically significant. The participant who is independent shows higher desire to go for facial plastic surgery ( $p$-value:0.021) (Table 2). In our population, the most common cosmetic intervention was Botox injection (41\%), and the most common facial plastic procedure was rhinoplasty (59\%). We measured the frequency of taking selfies and the association with the desire to do a facial plastic intervention. surprisingly, the majority (85\%) did not take regular selfies ( $>3$ times $\backslash$ day). Moreover, there was no statistically significant associated with the desire to go for plastic intervention ( $p$-value: 0.505) (Table 3). Currently, everyone relates the trending of facial plastic intervention to the era of advertising \& social media. As reasons our participants thought that what makes the facial plastic intervention trending in our population are: 
Table 1: Distribution of demographic variables of Participant $(n=399)$.

\begin{tabular}{|c|c|c|}
\hline Themes & Categories & Participant n (\%) \\
\hline \multirow{2}{*}{ Gender } & Male & $59(14.8)$ \\
\hline & Female & $340(85.2)$ \\
\hline \multirow{5}{*}{ Age } & Less than 20 & $40(10)$ \\
\hline & $21-30$ & $144(36.1)$ \\
\hline & $31-40$ & $101(25.3)$ \\
\hline & $41-50$ & $82(20.6)$ \\
\hline & More than 51 & $32(8)$ \\
\hline \multirow{4}{*}{ Educational Level } & High school & $65(16.3)$ \\
\hline & Bachelor's degree & $296(74.2)$ \\
\hline & Master's degree & $23(5.8)$ \\
\hline & $\mathrm{PhD}$ & $15(3.8)$ \\
\hline \multirow{4}{*}{ Marital Status } & Single & $170(42.6)$ \\
\hline & Married & $205(51.4)$ \\
\hline & Divorced & $20(5)$ \\
\hline & Widow & $4(1)$ \\
\hline \multirow{6}{*}{ Monthly Family income (SAR) } & Less than 5000 & $31(7.8)$ \\
\hline & $5000-10,000$ & $91(22.8)$ \\
\hline & $11,000-20,000$ & $127(31.8)$ \\
\hline & $21,000-30,000$ & $77(19.3)$ \\
\hline & $31,000-40,000$ & $32(8)$ \\
\hline & More than 41,000 & $41(10.3)$ \\
\hline
\end{tabular}

Table 2: Association between the monthly income \& the facial plastic surgery.

\begin{tabular}{|c|c|c|c|c|}
\hline \multirow[b]{2}{*}{ Themes } & \multirow[b]{2}{*}{ Categories } & \multicolumn{2}{|c|}{ Financial Status } & \multirow[b]{2}{*}{ P-Value } \\
\hline & & Independent & $\begin{array}{l}\text { Dependent on the Husband, } \\
\text { Father, Brother...etc. }\end{array}$ & \\
\hline \multirow{2}{*}{$\begin{array}{l}\text { Participants had plastic surgery } \\
\text { before or planning to have one }\end{array}$} & Yes & $189(61.6)$ & $118(38.4)$ & 0.021 \\
\hline & No & $45(48.9)$ & $47(51.1)$ & \\
\hline
\end{tabular}

Table 3: Association between taking selfies \& the desire to do a facial plastic procedure.

\begin{tabular}{|l|c|c|c|c|}
\hline \multirow{2}{*}{ Themes } & \multirow{2}{*}{ Categories } & \multicolumn{2}{|c|}{ The Frequency of Selfies Per Day } & \multirow{2}{*}{ P-Value } \\
\cline { 3 - 5 } & & Less Than Three Times & 3 or More Than Three Times & \\
\hline \multirow{2}{*}{$\begin{array}{c}\text { Participants had plastic surgery } \\
\text { before or planning to have one }\end{array}$} & Yes & $262(77.1)$ & $45(76.3)$ & 0.505 \\
\cline { 2 - 5 } & No & $78(22.9)$ & $14(23.7)$ & \\
\hline
\end{tabular}

a) The effect of social media influencers and celebrities $(72.2 \%)$,

b) Increased knowledge of surgeons and their ability to revise the surgery $(71.2 \%)$, c) The result of before and after pictures on social media $(65.7 \%)$,

d) Plastic surgeon self-advertisement (60.4\%) and (66.7\%) believe that self-portrait caused more awareness of the appearance of the face/nose (Table 4).

Table 4: Reasons behind trending of facial plastic surgery in our community.

\begin{tabular}{|c|c|c|}
\hline Themes & Categories & Participants' $\mathbf{n}(\%)$ \\
\hline \multirow{2}{*}{ To look better in Selfies/pictures } & Yes & $216(54.1)$ \\
\cline { 2 - 3 } & No & $183(45.9)$ \\
\hline \multirow{2}{*}{ Affected by snap chat fil } & Yes & $145(36.3)$ \\
\cline { 2 - 3 } & No & $254(63.7)$ \\
\hline
\end{tabular}




\begin{tabular}{|c|c|c|}
\hline \multirow{2}{*}{ Plastic surgeon self-advertisement } & Yes & $241(60.4)$ \\
\hline & No & $158(39.6)$ \\
\hline \multirow{2}{*}{ Before and after pictures on social media } & Yes & $262(65.7)$ \\
\hline & No & $137(34.3)$ \\
\hline \multirow{2}{*}{ Influenced by family or friends } & Yes & $237(59.4)$ \\
\hline & No & $162(40.6)$ \\
\hline \multirow{2}{*}{$\begin{array}{l}\text { Affected by social media influencers \& } \\
\text { celebrities. }\end{array}$} & Yes & $288(72.2)$ \\
\hline & No & $111(27.8)$ \\
\hline \multirow{2}{*}{$\begin{array}{c}\text { Reading articles or magazines about plastic } \\
\text { surgery }\end{array}$} & Yes & 167 (41.9) \\
\hline & No & $232(58.1)$ \\
\hline \multirow{2}{*}{ Cosmetic television programs } & Yes & $213(53.4)$ \\
\hline & No & $186(33.3)$ \\
\hline \multirow{2}{*}{$\begin{array}{l}\text { Did self-portrait cause more awareness of the } \\
\text { appearance of your face/nose }\end{array}$} & Yes & $266(66.7)$ \\
\hline & No & $133(33.3)$ \\
\hline \multirow{2}{*}{$\begin{array}{l}\text { Knowing the reduced morbidity from anesthesia } \\
\text { compared to previous years }\end{array}$} & Yes & $197(49.4)$ \\
\hline & No & $202(50.6)$ \\
\hline \multirow{2}{*}{$\begin{array}{l}\text { Increased expert surgeons and their ability to } \\
\text { revise the surgery }\end{array}$} & Yes & $284(71.2)$ \\
\hline & No & $115(28.8)$ \\
\hline \multirow{2}{*}{$\begin{array}{l}\text { To be more acceptable in the community, to } \\
\text { make friends, to get married or to find a job }\end{array}$} & Yes & $226(56.6)$ \\
\hline & No & $173(43.4)$ \\
\hline \multirow{2}{*}{$\begin{array}{l}\text { To be proud between friends, indicating your } \\
\text { wealthiness }\end{array}$} & Yes & $87(21.8)$ \\
\hline & No & $312(78.2)$ \\
\hline \multirow{2}{*}{ Having a better financial income } & Yes & $67(16.8)$ \\
\hline & No & $332(83.2)$ \\
\hline \multirow{2}{*}{ Mentality change of the family and society } & Yes & $146(36.6)$ \\
\hline & No & $253(63.4)$ \\
\hline
\end{tabular}

However, when we evaluate the factors affecting our patient's decision to go for facial plastic intervention it was: to look younger $(\mathrm{p} \leq 0.001)$, To boost self-esteem $(\mathrm{p}=0.004)$, and mimic friend's work $(p \leq 0.001)$ (Table 5). With the trend of snap chat filters and the mild changes created in facial features, we measure it effect on the decision to do the facial plastic intervention. Also, it was statistically

Table 5: Reasons for encouraging our patients to do plastic surgery. not significant (p-value: 0.106) (Table 6). We screened our patients for Body Dysmorphic Disorder, 77(19.3\%) Severe BDD, 151(37.8\%) Mild to moderate BDD and Non-BDD 171(42.9\%). We compare the sever BDD group with the rest, and there was no association with trending of facial plastic surgery (Table 7).

\begin{tabular}{|c|c|c|c|}
\hline P-value & $\begin{array}{l}\text { Participants had plastic surgery } \\
\text { before or planning to have one }\end{array}$ & Categories & Theme \\
\hline \multirow{2}{*}{$\leq 0.001$} & $138(45)$ & Yes & \multirow{2}{*}{ To look younger } \\
\hline & $169(55)$ & No & \\
\hline \multirow{2}{*}{0.004} & $153(49.8)$ & Yes & \multirow{2}{*}{ To boost self-esteem } \\
\hline & $154(50.2)$ & No & \\
\hline \multirow{2}{*}{0.175} & $209(68.1)$ & Yes & \multirow{2}{*}{ To correct some deformities } \\
\hline & $98(31.9)$ & No & \\
\hline \multirow{2}{*}{$\leq 0.001$} & $21(6.8)$ & Yes & \multirow{2}{*}{ Mimic friends work } \\
\hline & $286(93.2)$ & No & \\
\hline \multirow{2}{*}{0.147} & $50(16.3)$ & Yes & \multirow{2}{*}{$\begin{array}{l}\text { Significant other wanted your } \\
\text { (husband, job chance, friends }\end{array}$} \\
\hline & $257(83.7)$ & No & \\
\hline \multirow{2}{*}{0.04} & $107(34.9)$ & Yes & \multirow{2}{*}{ Milestone (wedding, party, event } \\
\hline & $200(65.1)$ & No & \\
\hline \multirow{2}{*}{0.079} & $60(19.5)$ & Yes & \multirow{2}{*}{ To follow the trend of beauty } \\
\hline & $247(80.5)$ & No & \\
\hline
\end{tabular}




\begin{tabular}{|l|l|l|c|}
\hline \multirow{2}{*}{0.344} & $111(36.2)$ & Yes & To relieve stress from social and \\
& family stress & No & 196(63.8) \\
\cline { 2 - 3 }
\end{tabular}

Table 6: Association between the effect of snapchat filter in the desire to go for facial plastic surgery.

\begin{tabular}{|c|c|c|c|c|}
\hline \multirow{2}{*}{ Themes } & \multirow{2}{*}{ Categories } & \multicolumn{2}{|c|}{ Due to Snap Chat Filters } & \multirow{2}{*}{ P-value } \\
\hline & & Yes & No & \\
\hline \multirow{2}{*}{$\begin{array}{l}\text { Participants had plastic } \\
\text { surgery before or planning } \\
\text { to have one }\end{array}$} & Yes & $106(34.5)$ & $201(65.5)$ & \multirow{2}{*}{0.106} \\
\hline & No & $39(42.4)$ & $53(57.6)$ & \\
\hline
\end{tabular}

Table 7: Association between body dysmorphic disorder and facial plastic surgery.

\begin{tabular}{|c|c|c|c|c|}
\hline \multirow{2}{*}{ Themes } & \multirow{2}{*}{ Categories } & \multicolumn{2}{|c|}{ BDD Score } & \multirow{2}{*}{ P-value } \\
\cline { 2 - 4 } & Negative, Mild \& Moderate & $63(20.5)$ & \multirow{2}{*}{0.164} \\
\hline \multirow{2}{*}{$\begin{array}{c}\text { Participants had plastic surgery } \\
\text { before or planning to have one }\end{array}$} & Yes & $244(79.5)$ & $14(15.2)$ & $78(84.8)$ \\
\cline { 2 - 4 }
\end{tabular}

\section{Discussion}

This current study intends to report the prevalence of facial plastic surgery and other cosmetic procedures in The Kingdom of Saudi Arabia, as well as the reasons behind the sudden increased demand for it along with their contributing factors. This paper, in our region, might be the first of its kind to study the association between the influence and effect of social media with the rate of cosmetic interventions as well as its' association with body dysmorphic disorder. Saudi Arabia recently has been experiencing a trend towards plastic surgery. According to the International Society of Aesthetic Plastic Surgeons (ISAPS), Saudi Arabia reported a performance number of 46,962 surgeries [1]. The current study showed that $34.8 \%$ had a cosmetic intervention. While a survey in Jeddah, Saudi Arabia has reported only 2.2\% of their study group undergoing cosmetic procedures [14]. In the United States, about 10.2 million cosmetic procedures were performed in 2005 [15]. The most ordinary cosmetic procedure in the study was Botox injection 41\%. A similar study conducted in Saudi Arabia by S. E. Alharethy showed $19 \%$ had Botox injection.16 Also, it was the most frequently reported cosmetic procedure in the United States as well with several 3,839,387 Botox injections [15]. As for plastic surgery, about $18 \%$ of the targeted population reported having surgical intervention previously, while $61.7 \%$ planned to have plastic surgery sometime in the future. Rhinoplasty was the most performed $60 \%$ as well as being the most wished for a procedure in the future $67 \%$. Our result matched the finding of ISAPS International Survey where they reported that Rhinoplasty is the fifth most commonly performed plastic surgery worldwide with several 298,413 rhinoplasties that were done in the United States [15].

Our data reveals that Saudi women and age more than 31 years were significantly associated with performing cosmetic procedures (p-value<0.001). Similarly, ASPS noted that $92 \%$ of the cosmetic patients were women and ages between 40-54 years [15]. A study in Turkey has also reported that young females were the most likely to perform these interventions 17 . As for the financial status, being financially dependent was highly associated for underwent cosmetic interventions and plastic surgery p-value $<0.001$, p-value $<0.05$ respectively. Higher economic status with a higher income was found to be significantly related to the prevalence of cosmetic interventions in Saudi Arabia as well [16]. When we review the literature to look for the top Reasons behind undergoing plastic surgery, multi studies reported that to look more beautiful is the primary motivation $[14,16]$. Another study done in al-Madinah said that $46 \%$ who had plastic surgery believe that social media affected their decision [14]. In another study, the primary motivating reason to have plastic intervention is influenced by family and friend (40\%) [17]. In contrast to our finding, Forty-two percent surgeons reported patients seeking cosmetic procedures to look better in selfies [10]. In our study, the overall prevalence of positive BDD in patients who had or are planning to have cosmetic surgery was about $20.5 \%$ [18]. Like multi-centric prospective study that assessed the prevalence of BDD among facial plastic and oculoplastic surgery patients in 3 sites, including academic practice and private practice, showed a prevalence of positive BDD around 37\%, 13\% in academic and private practice respectively [17]. A meta-analysis of 33 studies evaluate the prevalence of body dysmorphic disorder in plastic surgery, and dermatology patients report that $15.04 \%$ of plastic surgery patients were positive BDD [19].

\section{References}

1. Swami V, Chamorro Premuzic T, Bridges S, Furnham A (2009) Acceptance of cosmetic surgery: Personality and individual difference predictors. Body Image 6(1): 7-13.

2. (2016) American Society of Plastic Surgeons. Plastic Surgery Statistics Report - 2016 Cosmetic Plastic Surgery Statistics. Chicago.

3. (2015) ISAPS International Survey on Aesthetic / Cosmetic Procedures Performed in 2015. Hanover, New Hampshire.

4. (2016) Cosmetic Surgery National Data Bank Statistics.

5. Babuccu O, Latifoğlu O, Atabay K, Oral N, Coșan B (2003) Sociological aspects of rhinoplasty. Aesthetic Plast Surg 27(1): 44-49.

6. Blaivas JG, Levine MP, Murnen SK (2002) The effect of experimental presentation of thin media images on body satisfaction: A Meta-Analytic review. Int J Eat Disord 31(1): 1-16. 
7. Furnham A, Levitas J (2012) Factors that motivate people to undergo cosmetic surgery. Can J Plast Surg. The Canadian Journal of Plastic Surgery 20(4): 47-50.

8. Kubiak M, Lindberg A (2016) Slice me nice: A study exploring Swedish young women's views and responses to the marketing of Aesthetic Surgery in social media.

9. Montemurro P, Porcnik A, Hedén P, Otte M (2015) The influence of social media and easily accessible online information on the aesthetic plastic surgery practice: literature review and our own experience. Aesthetic Plast Surg 39(2): 270-277.

10. American Academy of Facial Plastic and Reconstructive Surgery. AAFPRS Annual Survey Unveils Rising Trends in Facial Plastic Surgery.

11. Oranges CM, Schaefer KM, Gohritz A, Haug MSD (2016) The Mirror Effect on Social Media Self-Perceived Beauty and Its Implications for Cosmetic Surgery. Plast Reconstr Surg Glob Open 4(11): e1088.

12. Ward B, Ward M, Fried O PB (2018) Nasal Distortion in Short-Distance Photographs: The Selfie Effect. JAMA Facial Plast Surg 20(4): 333-335.

13. Rastmanesh R, Gluck ME, Shadman Z (2009) Comparison of body dissatisfaction and cosmetic rhinoplasty with levels of veil practicing in Islamic women. Int J Eat Disord 42(4): 339-345.
14. Al Saiari A, Bakarman M (2015) Experiences and attitude among Saudi female University students towards cosmetic surgery. Journal of Taibah University Medical Sciences 10(4): 427-431.

15. (2015) American Society of Plastic Surgeons. Quick Facts Cosmetic and Reconstructive Plastic Surgery Trends.

16. Alharethy SE (2017) Trends and demographic characteristics of Saudi cosmetic surgery patients. Saudi Medical Journal 38(7): 738-741.

17. Joseph A, Ishii L, Joseph S, Smith J, Su P, et al. (2017) Prevalence of Body Dysmorphic Disorder and Surgeon Diagnostic Accuracy in Facial Plastic and Oculoplastic Surgery Clinics. JAMA Facial Plastic Surgery 19(4): 269-274.

18. Moosavizadeh SM, Niazi F, Kalantar Hormozi A (2012) Evaluation of Female Patients Motivating Factors for Aesthetic Surgery. World J Plast Surg 1(2): 76-82.

19. Ribeiro RVE (2017) Prevalence of Body Dysmorphic Disorder in Plastic Surgery and Dermatology Patients: A Systematic Review with MetaAnalysis. Aesthetic Plastic Surgery 41(4): 964-970.

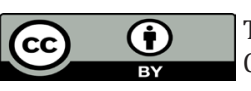

This work is licensed under Creative Commons Attribution 4.0 License

To Submit Your Article Click Here: Submit Article

DOI: $10.32474 /$ SJO.2019.01.000121 